\title{
1 Changes of microbial substrate metabolic patterns through a \\ 2 wastewater reuse process, including WWTP and SAT \\ 3 concerning depth
}

4

5 Yugo Takabe* ${ }^{1}$, Ippei Kameda, Ryosuke Suzuki, Fumitake Nishimura,

6 Sadahiko Itoh

7

8 Department of environmental engineering, Kyoto University, Kyoto-Daigaku-Katsura,

9 Nishikyo-ku, Kyoto, 6158540, Japan

10

11 *Corresponding author: Tel: +81-75-383-3256, Fax: +81-75-383-3256

12 Email address: takabe.yugo@t02.mbox.media.kyoto-u.ac.jp

13

14

15

16

17

18

1 Current affiliation: Recycling Research Team, Materials and Resources Research Group, Public Works Research Institue, 1-6 Minamihara, Tsukuba-shi, Ibaraki-ken, 305-8516, Tel: + 81-29-879-6765, Fax: 81-29-879-6797, Email: yu-takabe@pwri.go.jp

(C) 2014. This manuscript version is made available under the Elsevier user license http://www.elsevier.com/open-access/userlicense/1.0/ 


\section{Abstract}

20 In this study, changes of microbial substrate metabolic patterns by BIOLOG assay were

21 discussed through a sequential wastewater reuse process, which includes activated

22 sludge and treated effluent in wastewater treatment plant and soil aquifer treatment

23 (SAT), especially focusing on the surface sand layer in conjunction with the vadose

24 zone, concerning sand depth. A SAT pilot-scale reactor, in which the height of packed

25 sand was $237 \mathrm{~cm}$ (vadose zone: $17 \mathrm{~cm}$ and saturated zone $220 \mathrm{~cm}$ ), was operated and

26 fed continuously by discharged anaerobic-anoxic-oxic (A2O) treated water. Continuous

27 water quality measurements over a period of 10 months indicated that the treatment

28 performance of the reactor, such as $83.2 \%$ dissolved organic carbon removal, appeared

29 to be stable. Core sampling was conducted for the surface sand to a $30 \mathrm{~cm} \mathrm{depth}$, and

30 the sample was divided into six $5 \mathrm{~cm}$ sections. Microbial activities, as evaluated by

31 fluorescein diacetate, sharply decreased with increasing distance from the surface of the

$3230 \mathrm{~cm}$ core sample, which included significant decreases only $5 \mathrm{~cm}$ from the top surface.

33 A similar microbial metabolic pattern containing a high degree of carbohydrates was

34 obtained among the activated sludge, A2O treated water (influent to the SAT reactor)

35 and the 0-5 cm layer of sand. Meanwhile, the 10-30 cm sand core layers showed

36 dramatically different metabolic patterns containing a high degree of carboxylic acid

37 and esters, and it is possible that the metabolic pattern exhibited by the 5-10 $\mathrm{cm}$ layer is

38 at a midpoint of the changing pattern. This suggests that the removal of different organic 
39 compounds by biodegradation would be expected to occur in the activated sludge and in 40 the SAT sand layers immediately below $5 \mathrm{~cm}$ from the top surface. It is possible that 41 changes in the composition of the organic matter and/or transit of the limiting factor for 42 microbial activities from carbon to phosphorus might have contributed to the observed 43 dramatic changes in SAT metabolic patterns.

\section{Keywords}

47 Wastewater reuse, Soil aquifer treatment, Surface sand layer, Activated sludge, 48 BIOLOG assay, Microbial substrate metabolic pattern 


\section{1. Introduction}

60 Inadequate water supply and deterioration of water quality are serious problems in

61 many parts of the world. These problems are attributed to population growth in urban

62 areas, contamination of surface water and groundwater, uneven distribution of water

63 sources and frequent droughts because of extreme global weather patterns (Asano and

64 Cotruvo, 2004). Wastewater reuse is one of the realistic solutions to the abovementioned 65 problems.

66

67 Soil aquifer treatment (SAT) offers advantages such as low cost, underground storage of

68 reclaimed water and the potential for water quality improvement through infiltration

69 (Asano and Cotruvo, 2004; Asano et al., 2007). Actual wastewater reuse systems using

70 SAT include the 'Groundwater Replenishment System' in California and the

71 'Sweetwater Recharge Facilities' in Arizona (USA) and the 'Dan Region Sewage

72 Reclamation Project' in Israel (Chalmers and Patel, 2013; Oren et al., 2007; Quanrud et

73 al., 2003). Reclaimed water has been used for such applications as potable and irrigation

74 water.

75

76 It is widely known that water replenishment using the water reuse systems strongly

77 depends on microbial decomposition, including not only WWTP but also SAT (Drewes

78 and Fox, 1999; Xue et al., 2009; Zhang et al., 2012). A lot of past studies focused on 
79 microbial transformation processes in WWTP (e.g. Xue et al. 2010; Al-Mutairi, 2009;

80 Guckert, et al., 1996) and SAT (Alfreider et al., 1997; Kolehmainen et al., 2009;

81 Långmark et al., 2004; Zhang et al., 2012), respectively. Moreover, the transformation

82 processes would change in WWTP and SAT, which consists of sequential water reuse

83 that replenishes the reused water qualities. However, there were few studies that focused

84 on the changes in the microbial processes in WWTP and SAT from the viewpoint of

85 WWTP and SAT being a sequential water reuse process.

86

87 Microbial transformation processes in SAT were characterized by the conversion rate of

88 certain chemicals by microbes (Alfreider et al., 1997; Långmark et al., 2004),

89 extracellular enzyme activities (Kolehmainen et al., 2009) and the range of used

90 substances using the BIOLOG assay (Zhang et al., 2012). These studies analysed the

91 changes in the transformation processes throughout the entire SAT system, and samples,

92 including water and soil, were collected at discrete distances. In addition, the removal of

93 organic matter in SAT occurred in the soil surface layer including the vadose zone

94 (Drewes and Fox, 1999; Quanrud et al., 1996; Quanrud et al., 2003; Zhang et al., 2012).

95 Therefore, dynamic changes in the microbial transformation processes are expected in

96 these layers. However, this is also not well understood (Schütz et al., 2010).

98 The BIOLOG assay is simple and yields a great deal of information for the 
99 characterization of microbial transformation processes (Campbell et al., 1997; Salomo

100 et al., 2009). A single substrate, redox dye tetrazolium violet and nutrients are supplied

101 in well plates. The colour production from the reduction of tetrazolium violet is used as

102 an indicator of the metabolism of the substrates. Moreover, the microbial transformation

103 processes are characterized on the basis of the substrate metabolic pattern (Garland and

104 Mills, 1991; Salomo et al., 2009). The BIOLOG assay has been used in different media,

105 collected from different locations, including natural soil (Campbell et al., 1997; Garland

106 and Mills, 1991), soil from constructed wetlands and SAT (Salomo et al., 2009; Weber

107 and Legge, 2011; Zhang et al., 2012), freshwater (Garland and Mills, 1991) and

108 activated sludge (Al-Mutairi, 2009; Guckert, et al., 1996) to compare and discuss the

109 substrate metabolic patterns.

110

111 Based on the above-mentioned background, treated wastewater was continuously

112 discharged to a SAT pilot-scale reactor in an actual WWTP, and the following objectives

113 were considered using the BIOLOG assay: (1) to comprehend the changes in microbial

114 transformation processes through a sequential wastewater reuse process, including

115 activated sludge and treated effluent in WWTP and SAT, looking at the soil depth,

116 surface layer and the vadose zone, (2) to discuss relations between changes in the

117 processes and water quality parameters. In addition, Hazen et al. (1991) determined that

118 the number of bacteria in sediment $\left(1.00 \times 10^{6}\right.$ to $5.01 \times 10^{8}$ bacteria/g dry $)$ was much 
119 higher than that in the adjacent groundwater $\left(1.00 \times 10^{3}\right.$ to $6.31 \times 10^{4}$ bacteria/mL).

120 Therefore, microbes in SAT soil were evaluated in this study.

123 2. Materials and methods

124 2.1. Pilot-scale reactor

125 A stainless steel pilot-scale reactor was set in an actual wastewater treatment plant in

126 Kyoto Prefecture, and a diagram of the reactor is shown in Figure 1. The reactor was

127 cuboidal and its width, depth and height were 150, 150 and $300 \mathrm{~cm}$, respectively

128 (volume: $6.75 \times 10^{6} \mathrm{~cm}^{3}$ ).

129

130 Sand, which was collected in Shiga Prefecture, was purchased and packed in the reactor,

131 and its characteristics are listed in Table A1. The reactor operations began on 20

132 October 2011. The height of the packed sand was initially $250 \mathrm{~cm}$, but the surface sank

133 immediately after the initiation of operations. The height of the sand surface appeared to

134 be stable after approximately 1 month at $237 \mathrm{~cm}$. A final effluent port was set at an

135 elevation of $220 \mathrm{~cm}$ from the bottom of the plant. Therefore, the thicknesses of the

136 vadose zone and saturated zone in the reactor were 17 and $220 \mathrm{~cm}$, respectively. The

137 reactor also had two side ports at depths of 87 (Port 1) and $187 \mathrm{~cm}$ (Port 2), respectively,

138 from the sand surface to collect water and sand samples at the given depths. 
139 The influent water to the reactor was effluent of an anaerobic-anoxic-oxic (A2O)

140 process, which is mainly used to treat domestic wastewater. The influent to the SAT

141 reactor was collected by a hose attached to a $0.05 \mathrm{~cm}$ mesh from a $100 \mathrm{~cm}$ depth in the

142 final sedimentation tank before chlorination. The hydraulic retention time (HRT) of the

143 A2O process was $2.8 \mathrm{~h}$ in the anaerobic tank, $2.8 \mathrm{~h}$ in the anoxic tank and $5.6 \mathrm{~h}$ in the

144 aerobic tank, and the solid retention time (SRT) was 9.5 days.

145

146 First, the influent to the SAT reactor was piped into a storage tank made of polyethylene

147 and exposed to the atmosphere in the tank. And then, it was continuously pumped into

148 the reactor through a PTMG tube (Aoi, Japan). The Influent to the SAT reactor was

149 dripped using a final port, which was located at a height of $60 \mathrm{~cm}$ from the centre of the

150 sand surface. The influent to the SAT reactor was continuously discharged without

151 interruption.

152

153 The HRT was set at 30 days, and the inflow rate was $70 \mathrm{~L} /$ day.

\section{2.2. Continuous water quality measurement}

156 Water samples of the influent to the SAT reactor and effluents from Port 1, Port 2 and

157 the final effluent port were collected once every two weeks, in principal, from 4

158 November 2012 to 6 September 2013. The measured water quality parameters included 
$159 \mathrm{pH}(\mathrm{n}=26)$, dissolved oxygen (DO) $(\mathrm{n}=26)$, dissolved organic carbon (DOC) $(\mathrm{n}=29)$,

$160 \mathrm{UV}_{254}(\mathrm{n}=29)$, nitrogen species (dissolved total nitrogen [DTN], $\mathrm{NH}_{4}^{+}, \mathrm{NO}_{2}^{-}, \mathrm{NO}_{3}{ }^{-}$

161 and organic $\mathrm{N}$ [as the difference between DTN and total inorganic N]) $(\mathrm{n}=20)$,

162 dissolved total phosphorus (DTP) $(n=20)$, as well as water temperature $(n=126)$ of the

163 influent to the SAT reactor and the final effluent from the SAT reactor. With respect to

164 the influent to the SAT reactor, a sample for each parameter, except $\mathrm{pH}$ and DO, was

165 collected just after the final port, which was located at a height of $60 \mathrm{~cm}$ from the centre

166 of the sand surface, whereas the sample for $\mathrm{pH}$ and DO was collected in the storage tank

167 to prevent DO from increasing during sampling. Prior to the measurement of the water

168 qualities, except for $\mathrm{pH}$ and $\mathrm{DO}$, the water samples had been filtered by GF/B with a

169 pore size of $1 \mu \mathrm{m}$ (Whatman, USA).

170

171 The $\mathrm{pH}$ and DO were measured by D-52 and D-55 (Horiba, Japan) multi-parameter

172 metres, respectively. The DOC and $\mathrm{UV}_{254}$ were measured by a TOC-L analyzer

173 (Shimadzu, Japan) and a Multi-Spec-1500S spectrophotometer (Shimadzu, Japan),

174 respectively. The specific ultraviolet absorbance (SUVA) was calculated by dividing the

$175 \mathrm{UV}_{254}$ value by the DOC. DTN and DTP were measured by an AACS-II auto-analyzer

176 (Bran+Luebbe, Germany). The nitrogen component $\mathrm{NH}_{4}{ }^{+}$were measured by an AA-II

177 auto-analyzer (Bran+Luebbe, Germany), and $\mathrm{NO}_{2}{ }^{-}$and $\mathrm{NO}_{3}{ }^{-}$were measured by an

178 AA-III auto-analyzer (Bran+Luebbe, Germany). Water temperature was measured by a 
181 The effluents from Port 1, Port 2 and the final effluent port are referred to as effluent $182(87 \mathrm{~cm})$ from the SAT reactor, effluent $(187 \mathrm{~cm})$ from the SAT reactor and final effluent $183(237 \mathrm{~cm})$ from the SAT reactor, respectively, in this study.

185 2.3. Evaluation of microbial substrate metabolic patterns

\section{$186 \quad$ 2.3.1. Sampling scheme}

187 Samples, including the water and sand samples described below, were collected four

188 times in the summer for reproducibility.

190 Activated sludge from the aerobic tank of the A2O process, influent to the SAT reactor 191 and sand samples from the SAT reactor were collected on 29 July and 5, 12 and 19

192 August 2013. The water temperatures at each sampling event were similar, ranging from 19327.3 to $30.9^{\circ} \mathrm{C}$.

195 The activated sludge was collected with a plastic ladle and preserved in a sterilized 196 polypropylene (PP) vial (Vioramo, AS ONE, Japan). The collected samples were used 197 for BIOLOG assay, fluorescein diacetate (FDA) assay and for the water quality 198 measurements, described below. 
199 The influent to the SAT reactor was collected using the PP vial for BIOLOG assay and 200 FDA assay and glass bottles for the water quality measurements.

201

202 Core sampling was conducted to collect the surface sand down to a $30 \mathrm{~cm}$ depth using a 203 liner sampler (DIK-110C, Daiki Rika Kogyo, Japan) with a $5 \mathrm{~cm}$ diameter and $30 \mathrm{~cm}$ 204 height. The liner sampler and its sampling tube were sterilized at $250^{\circ} \mathrm{C}$ for $2 \mathrm{~h}$ and 205 using $10 \mathrm{mg}-\mathrm{NaHOCl} / \mathrm{L}$ overnight, respectively. The $150 \mathrm{~cm} \times 150 \mathrm{~cm}$ area of the sand 206 surface was divided into $10 \mathrm{~cm} \times 10 \mathrm{~cm}$ sections, and the $30 \mathrm{~cm}$ depth sand core sample 207 was collected at a grid point. The four sample collections were conducted at different 208 grid points within $15 \mathrm{~cm}$ from the position of the final port.

210 The sand core sample was divided into six segments of $5 \mathrm{~cm}$ lengths (denoted as the 211 0-5 cm layer, 5-10 cm layer, 10-15 cm layer, 15-20 cm layer, 20-25cm layer and 212 25-30 cm layer) in the laboratory, and each layer was collected in a sterilized glass 213 beaker. The sand was well mixed with sterilized stainless spoons in the beaker and used 214 as sand samples. The beakers and spoons were sterilized at $250^{\circ} \mathrm{C}$ for $2 \mathrm{~h}$ in advance.

216 A 30-cm-deep hole was also created by the liner sampler at a point that was located 70 $217 \mathrm{~cm}$ from the position of the final port, and a water sample taken from an approximately $21825 \mathrm{~cm}$ depth from the top surface (denoted as effluent $(25 \mathrm{~cm})$ from the SAT reactor) 
219 was collected with a PP syringe and tubes and stored in the PP vial. This sampling was 220 conducted five times from 12 August to 26 August 2013.

221

222 Sand and water samples were collected from Port 1 and Port 2 with PP vials. After the 223 sand mixed with the treated water, which flowed away from Port 1 and Port 2, was left 224 to rest for $30 \mathrm{sec}$, the supernatant was decanted to another PP vial, and the resulting 225 sand and supernatant were used as sand and water samples, respectively. The sand and 226 water samples from Port 1 were denoted as $87 \mathrm{~cm}$ layer and effluent $(87 \mathrm{~cm})$ from the 227 SAT reactor, respectively, and the sand and water samples from Port 2 were denoted as $228187 \mathrm{~cm}$ layer and effluent $(187 \mathrm{~cm})$ from the SAT reactor, respectively.

\section{$230 \quad$ 2.3.2. TOC measurement in sand}

231 The total organic carbon (TOC) of each collected sand sample was measured using a 232 SSM-5000A solid sample combustion unit (Shimadzu, Japan).

\section{$234 \quad$ 2.3.3. FDA assay}

235 Several enzymes produced by microbes, such as protease, lipase and esterase, can 236 catalyse the transformation of fluorescein diacetate $\left(3^{\prime}, 6^{\prime}\right.$-diacetylfluorescein (FDA)) to 237 fluorescein, and the FDA assay was used to assess the total microbiological activity 238 (Ichikawa et al., 2002; Schnürer and Rosswall, 1982; Weber and Legge, 2011). FDA 
239 assay was applied to the activated sludge, influent to the SAT reactor and each sand 240 layer sample, in reference to Ichikawa et al., (2002) and Schnürer and Rosswall, (1982).

242 A $20 \mathrm{~mL}$ volume of $60 \mathrm{mM}$ sterile sodium phosphate buffer (pH 7.6) was added to each

$2435 \mathrm{~g}$-wet sand sample, $1 \mathrm{~mL}$ activated sludge and $5 \mathrm{~mL}$ influent to the SAT reactor. After 244 addition of $0.3 \mathrm{~mL}$ of FDA solution ( $2 \mathrm{mg}$ FDA and $2 \mathrm{~mL}$ acetone), the samples were 245 shaken for $1 \mathrm{~h}$. The amount of FDA to be added was determined based on the amount 246 sufficient for microbes in the $5 \mathrm{~g}$-wet sample of the 0-5 cm sand layer, whose activity 247 was the highest. Immediately after shaking for $1 \mathrm{~h}$, the sample was filtered using a No.1 248 filter (Advantec, Japan) followed by a polytetrafluoroethylene (PTFE) membrane filter 249 with a pore size of $0.2 \mu \mathrm{m}$ (Advantec, Japan). The amount of fluorescein was measured 250 as the absorbance at $490 \mathrm{~nm}$ by the Multi-Spec-1500S. The same process using samples 251 sterilized by autoclave at $120^{\circ} \mathrm{C}$ for $20 \mathrm{~min}$ was repeated for use as blank samples, and 252 the absorbance of the sterile sample was subtracted. A strong relationship was found 253 between the microbial amount and the absorbance $\left(y=0.0192, R^{2}=0.995: x=g\right.$-wet of 254 sand, $y=$ absorbance) using 1, 2, 3, 4 and 5 g-wet of the sand samples taken from a $1 \mathrm{~cm}$ 255 depth from the top surface.

256

\section{2.3.4. BIOLOG assay with EcoPlate}

258 EcoPlate (Biolog Inc. U.S.) was used to evaluate and compare microbial substrate 
259 metabolic patterns among the samples.

260

261 The activated sludge and influent to the SAT reactor were diluted 100 and 10 times with 262 the $60 \mathrm{mM}$ sterile sodium phosphate buffer, respectively, and $150 \mu \mathrm{L}$ of the diluted 263 samples were inoculated to the plates.

264

265 The suspension of microbes in the sand was conducted with a Waring blender (Ace 266 homogenizer AM-3, Nihonseiki, Japan). A mixture of 10 g-wet of each sand sample and $26740 \mathrm{~mL}$ of the phosphate buffer were blended in the blender for $3 \mathrm{~min}$. The homogenate was centrifuged for $1 \mathrm{~min}$ at $1500 \mathrm{rpm}$ (KUBOTA 5200, Kubota, Japan) to remove the sand particles, and $150 \mu \mathrm{L}$ of the supernatant was inoculated to the plate.

271 EcoPlates were incubated at $25^{\circ} \mathrm{C}$ in an incubator (IS-41, Yamato, Japan) for 7 days, 272 and wet papers were set at the bottom of the incubator to prevent dryness.

274 Absorbance was measured using a Powerscan-PC (DS Pharma Biomedical, Japan) at $275590 \mathrm{~nm}$ after the inoculation of the plates every $3 \mathrm{~h}$ during the first period of 5 days and $2766 \mathrm{~h}$ during the last 2 days. The absorbance was also measured every $1.5 \mathrm{~h}$ during the 277 first period for samples, in which the absorbance rapidly increased. 
279 The absorbance data were corrected by subtraction of the blank well data at each 280 sampling time. Average well colour development (AWCD) was calculated for each

281 sample at each time, and the absorbance data in each well was normalized by dividing 282 by the AWCD to compensate for the influences of inoculum density (Garland, 1996; 283 Rutgers et al., 2008).

285 Salomo et al., (2009) determined microbial substrate metabolic patterns from a 286 constructed wetland using the data at $\mathrm{AWCD}=0.2$ when the substrate utilization rates 287 were situated in the transition from lag phase to exponential phase. In this study, the 288 normalized absorbance data for each sample at each sampling date with AWCD $=0.2$ 289 was analysed by principal component analysis to evaluate and compare microbial 290 substrate metabolic patterns among the samples.

291

292 It is known that bacteria are one component of biomass in activated sludge and soil 293 (Thawornchaisit and Pakulanon, 2007; Wardle, 1992). Therefore, BIOLOG assay was 294 also applied to the activated sludge with different dilution levels to ensure that 295 normalization by the AWCD compensated for the influences of inoculum densities. 296 Nippon Steel \& Sumikin Eco-Tech (Japan) measured 16S rRNA copies by real-time 297 PCR for the activated sludge, influent to the SAT reactor and the phosphate buffer after 298 the extraction of each sand layer on 19 August (DNA extraction with Extrap Soil DNA 
299 Kit Plus ver. 2 [Nippon Steel \& Sumikin Eco-Tech, Japan] and quantification with 300 PicoGreen ${ }^{\circledR}$ dsDNA assay kit [Invitrogen, US]). There were two digit differences in the 301 copy numbers among the samples (Table 1). Therefore, activated sludge samples diluted 30210,100 and 1000 times were assayed and analysed by principal component analysis 303 with the other samples on 19 August.

304

305 2.3.5. Water quality measurements

306 The $\mathrm{pH}$ and DO (except for effluent $(25 \mathrm{~cm})$ from the SAT reactor) and DOC, $\mathrm{UV}_{254}$, 307 nitrogen species and DTP after filtration with GF/B were measured for each water 308 sample. The measurement methods were the same as described in Section 2.2. In 309 addition, fluorescence spectra were collected for the filtered samples on 12 August. The 310 samples were diluted to $0.7 \mathrm{mgC} / \mathrm{L}$ and adjusted to $\mathrm{pH}$ 7. To obtain excitation-emission 311 matrix (EEM) profiles, excitation wavelengths were incremented from 220 to $400 \mathrm{~nm}$ in $3125 \mathrm{~nm}$ steps, and for each excitation wavelength, the emission was detected from 240 to $313500 \mathrm{~nm}$ in $5 \mathrm{~nm}$ steps. Fluorescence of super purified water as a blank sample was 314 subtracted from each spectrum.

315

316 Suspended solid (SS): $105^{\circ} \mathrm{C}$ for $2 \mathrm{~h}$ and volatile suspended solid (VSS): $600^{\circ} \mathrm{C}$ for 30

317 min were measured for the activated sludge and treated wastewater (Japan Sewage 318 Works Association, 1997). 


\section{2.4. Statistical analysis}

320 The Wilcoxon rank sum test was used to examine the statistical significance of the

321 measured sand and water quality indexes between two samples at subsequent points

322 along the flow path, such as the influent to the SAT reactor vs. effluent $(25 \mathrm{~cm})$ from the

323 SAT reactor and 0-5 cm layer vs. 5-10 cm layer. A significance level of 0.05 was used 324 for all tests.

327

\section{Results and discussion}

\subsection{Temporal changes in water qualities}

329 Temporal changes of the water qualities of each water sample are shown in Figure2-1

330 and 2-2. The distribution of each quality is arranged in order of the influent to the SAT

331 reactor, effluent $(87 \mathrm{~cm})$ from the SAT reactor, effluent $(187 \mathrm{~cm})$ from the SAT reactor

332 and final effluent $(237 \mathrm{~cm})$ from the SAT reactor unless otherwise noted, and median,

333 minimum and maximum values for each index are formatted as median

334 (minimum-maximum) in this section.

335

336 The $\mathrm{pH}$ varied $6.58(6.16-7.67), 6.70(5.88-7.03), 5.79(5.31-6.52)$ and 5.64

337 (5.28-6.03), respectively. There were no significant differences between the influent to 338 the SAT reactor and effluent $(87 \mathrm{~cm})$ from the SAT reactor $(p>0.05)$. Meanwhile, $\mathrm{pH}$ 
339 significantly decreased from effluent $(87 \mathrm{~cm})$ from the SAT reactor to effluent $(187 \mathrm{~cm})$

340 from the SAT reactor and from effluent $(187 \mathrm{~cm})$ from the SAT reactor to final effluent

$341(237 \mathrm{~cm})$ from the SAT reactor $(p<0.05)$. There were no noticeable seasonal changes in 342 each water sample.

343

344 When 10 g-wet sterilized sand was shaken with $40 \mathrm{~mL}$ of sterile influent to the SAT 345 reactor for $12 \mathrm{~h}$, the $\mathrm{pH}$ in the influent to the SAT reactor was found to decrease from 3467.34 to 6.16 . Based on this result, the decrease of $\mathrm{pH}$ in the plant was partially caused 347 by the original sand characteristics, such as ion exchanges.

349 The DO ranged $3.36(1.12-6.70), 7.87(3.32-10.6), 4.38(1.28-9.18)$ and 4.52

$350(1.30-7.56) \mathrm{mgO}_{2} / \mathrm{L}$, respectively. The $\mathrm{DO}$ of the effluent $(87 \mathrm{~cm})$ from the SAT reactor 351 was significantly higher than that of the influent to the SAT reactor $(p<0.05)$, and the 352 increase can be partially attributed to the contact of the influent to the SAT reactor with 353 air trapped in the sand voids of the vadose zone. DO significantly decreased thorough 354 percolation from the 87 to $187 \mathrm{~cm}$ depth $(p<0.05)$. Meanwhile, there were no significant 355 differences in DO between the effluent $(187 \mathrm{~cm})$ from the SAT reactor and final effluent $356 \quad(237 \mathrm{~cm})$ from the SAT reactor $(p>0.05)$.

358 Figure 2-1 also shows that DO in each effluent adversely increased and decreased 
359 against the water temperature of the final effluent $(237 \mathrm{~cm})$ from the SAT reactor.

360 Therefore, changes in the saturated oxygen concentration of water because of the 361 temperature might influence the DO of each effluent.

362

363 Based on the results, DO in each effluent mostly exceeds $2 \mathrm{mgO}_{2} / \mathrm{L}$, and it was 364 determined that the entire reactor operated under aerobic conditions.

366 The distribution of DOC was $3.91(2.85-4.55), 1.02(0.781-1.57), 0.734(0.560-1.32)$

367 and $0.658(0.482-0.870) \mathrm{mgC} / \mathrm{L}$, respectively, and DOC significantly decreased in each 368 effluent through the percolation path in the reactor $(p<0.05)$. In comparison with the 369 median values of the influent to the SAT reactor, DOC removal percentages were $73.7 \%$, $37081.3 \%$ and $83.2 \%$. Drewes and Fox (1999) obtained 76\% DOC removal (from 11.5 $371 \mathrm{mgC} / \mathrm{L}$ to $2.8 \mathrm{mgC} / \mathrm{L}$ ) for the secondary effluent after 21 days percolation. In addition, 372 Zhang et al., (2012) obtained 79\% DOC removal (from $4.31 \mathrm{mgC} / \mathrm{L}$ to $0.91 \mathrm{mgC} / \mathrm{L}$ ) for 373 ozonated secondary effluent after 28.8 days retention. The DOC removal of the final 374 effluent $(237 \mathrm{~cm})$ from the SAT reactor in the present study is similar to these values 375 over a similar HRT. DOC was slightly low in the influent to the SAT reactor in the 376 summer season from June to September. Meanwhile, there were no noticeable seasonal 377 changes in each effluent through the sampling period. 378 
$379 \mathrm{UV}_{254}$ ranged $0.088(0.046-0.128), 0.027(0.008-0.062), 0.024(0.008-0.048)$ and 0.023

$380(0.005-0.052) \mathrm{cm}^{-1}$, respectively. There was a significant decrease from the influent to 381 the SAT reactor to the effluent $(87 \mathrm{~cm})$ from the SAT reactor $(p<0.05)$, which indicate 382 the removal of the aromatic components through $87 \mathrm{~cm}$ percolation from the top surface. 383 Meanwhile, there were no significant differences between effluent $(87 \mathrm{~cm})$ from the 384 SAT reactor and effluent $(187 \mathrm{~cm})$ from the SAT reactor and effluent $(187 \mathrm{~cm})$ from the 385 SAT reactor and final effluent $(237 \mathrm{~cm})$ from the SAT reactor $(p>0.05)$. There were no 386 noticeable seasonal changes in each water sample through the sampling period. 387

388 The distribution of SUVA was $0.022(0.013-0.035), 0.025(0.0078-0.061), 0.030$ $389(0.0099-0.065)$ and $0.033(0.0077-0.079) \mathrm{L} /(\mathrm{mgC} \cdot \mathrm{cm})$. There was a significant increase 390 from the influent to the SAT reactor to the effluent $(87 \mathrm{~cm})$ from the SAT reactor $391(p<0.05)$. Therefore, it was found that non-aromatic components were preferentially 392 removed during organic matter removal through $87 \mathrm{~cm}$ percolation. Meanwhile, there 393 were no significant differences below the $87 \mathrm{~cm}$ depth $(p>0.05)$. There were no 394 noticeable seasonal changes in each water sample.

396 DTN ranged $4.58(3.36-7.50), 4.62(3.56-8.14), 4.43(2.90-6.83)$ and 4.69 (3.79-6.29) $397 \mathrm{mgN} / \mathrm{L}$, respectively, and no significant differences were observed among the water 398 samples $(p>0.05)$. In addition, using median values, $\mathrm{NO}_{3}{ }^{-}$accounted for $78.3 \%, 92.3 \%$, 
$39996.6 \%$ and $88.9 \%$ of DTN in each water sample. DTN was comparatively high in each 400 water sample during the winter season from December to March.

401

402 The distribution of DTP was $0.206(0.090-1.13) \mathrm{mgP} / \mathrm{L}$ in the influent to the SAT 403 reactor. Meanwhile, it was not detected $(<0.002 \mathrm{mgP} / \mathrm{L})$ in each effluent. DTP was high 404 in the influent to the SAT reactor during the summer season from June to September. Ak 405 and Gunduz (2013b) showed that $\mathrm{PO}_{4}{ }^{3-}$ precipitated in the soil surface. $\mathrm{PO}_{4}{ }^{3-}$ accounted 406 for $56 \pm 21 \%$ (average \pm standard deviation, $n=34$ ) in DTP in the influent to the SAT 407 reactor (Kyoto City Waterworks Bureau); therefore, the $\mathrm{PO}_{4}{ }^{3-}$ precipitation might have 408 contributed to the decrease in DTP in the SAT reactor.

410 The median mole ratio $\mathrm{C}: \mathrm{N}: \mathrm{P}$ of the influent to the SAT reactor during the period from 411 June to September, when DOC decreased and DTP increased, was 100:129:4.02, while 412 for all other periods it was 100:115:12.7. Therefore, it was determined that carbon was 413 the limiting factor for microbial activities in the influent to the SAT reactor, despite the 414 observed decrease and increase. Meanwhile, the median C:N:P ratio was $415100: 483:<0.196,100: 634:<0.273$ and100:734: $<0.304$ for effluent $(87 \mathrm{~cm})$ from the SAT 416 reactor, effluent $(187 \mathrm{~cm})$ from the SAT reactor and final effluent $(237 \mathrm{~cm})$ from the 417 SAT reactor, respectively, through the entire period, and was determined that 418 phosphorus was the limiting element. 
419 Based on these results, it was determined that the treated effluents from the SAT reactor

420 exhibited no noticeable seasonal variations, except for slightly high DTN in the winter

421 season, and the treatment performance appeared to be stable under aerobic conditions,

422 including the sampling period for the analysis of the metabolic patterns.

423

424 3.2. Changes of microbial substrate metabolic patterns

$425 \quad 3.2 .1 . T O C$ in the sand along the flow path

426 Ranges of TOC for all sand samples are listed in Table 1. Median TOC in the $0-25 \mathrm{~cm}$

427 layers was high in comparison with a TOC of $0.0094 \%$ in the sand before reactor

428 packing (Table A1). In addition, TOC in the $0-5 \mathrm{~cm}$ layer was significantly higher than

429 that of the 5-10 cm layer $(p<0.05)$. This indicates that microbial growth and organic

430 adsorption occurs in the layers through operation, especially in the $0-5 \mathrm{~cm}$ layer. The 87

$431 \mathrm{~cm}$ and $187 \mathrm{~cm}$ layers exhibited lower TOC values than that before packing, which

432 indicates that organic matter and microbes originally adsorbed were washed out by

433 percolation of the treated water cleaned by the above layers.

\section{$435 \quad$ 3.2.2. Microbial activities by FDA assay}

436 The results of FDA assay are listed in Table 1. The microbial activity of the activated

437 sludge and the $0-5 \mathrm{~cm}$ layer was significantly higher than that of the influent to the SAT

438 reactor $(p<0.05)$. The maximum weight of water in the $0-5 \mathrm{~cm}$ layer sample was $0.16 \mathrm{~g}$ 
439 in a $1 \mathrm{~g}$-wet sand sample, and the absorbance was below $0.005 \mathrm{~g}^{-1}$ in the influent to the 440 SAT reactor, based on a water density of $1 \mathrm{~g} / \mathrm{mL}$. Therefore, under conditions where the 441 bulk water in the $0-5 \mathrm{~cm}$ layer sample was the influent to the SAT reactor, the microbial 442 activity of the influent to the SAT reactor could be calculated as less than $0.0008 \mathrm{~cm}^{-1}$ 443 in $1 \mathrm{~g}$-wet of sand. Meanwhile, the minimum absorbance of the $0-5 \mathrm{~cm}$ layer was 0.044

$444 \mathrm{~cm}^{-1} \cdot \mathrm{g}_{\text {-wet }}{ }^{-1}$. Therefore, the sample should contain some active microbes which were 445 directly discharged from the influent to the SAT reactor into the $0-5 \mathrm{~cm}$ layer. However, 446 the assay determined that this contribution to the overall activity in the $0-5 \mathrm{~cm}$ layer 447 was very small (less than 1/50).

449 The SAT microbial activity sharply decreased over the flow path, and this corresponds 450 to the TOC trend. In comparison to the median absorbance of the $0-5 \mathrm{~cm}$ layer, the 451 absorbance of the $5-10 \mathrm{~cm}$ layer was $47 \%$ thereof and significantly low $(p<0.05)$. In 452 addition, low absorbance was obtained in the 10-15 cm layer (13\%) and 15-20 cm layer $453(5.6 \%)$.

\section{3.2.3. Microbial substrate metabolic pattern}

456 Figure A1 shows the AWCD of each sample at each sampling date. AWCD in activated 457 sludge, influent to the SAT reactor and 0-5 $\mathrm{cm}$ layer increased more rapidly than the 458 other samples. 
459 Figure 3 shows the results of the principal component analysis. In addition, Table A2 460 shows the principal component loading rate of each substrate, and the 31 substrates 461 were classified based on their structure, in reference to previous reports (Salomo et al., 462 2009; Zhang et al., 2012).

464 The contribution ratio of the first and second principal component ranged from $61.3 \%$ 465 to $71.6 \%$ and from $12.3 \%$ to $14.9 \%$, respectively. The first principal component 466 exhibited much in common with substrates whose loading rate exceeded 0.5 (Sala et al., 467 2005) among the sampling dates. Data plots of microbes with substantial metabolism 468 for the following substrates are located in the positive direction on the first principal 469 component axis: carboxylic acids (4-hydroxy benzonic acid, itaconic acid and $470 \gamma$-hydroxybutyricacid), amino acids ( $\mathrm{L}$-asparagine, $\mathrm{L}$-phenylalanine and $\mathrm{L}_{\mathrm{L}}$-threonine), 471 polymers (Tween 40 and Tween 80 ) and esters (pyruvic acid methyl ester). Meanwhile, 472 those with substantial metabolism for the following substrates are located in the 473 negative direction: carbohydrates (D-cellobiose, $\mathrm{D}^{- \text {-mannitol, }}$ $474 N$-acetyl-D-glucosamine, $\alpha$-D-lactose and $\beta$-methyl-D-glucoside), amino acids ( $\mathrm{L}_{\text {-Serine }}$ ), 475 polymers (glycogen) and phoshorylated chemicals (DL- $\alpha-$ glycerol phosphate). Roughly 476 speaking, microbes with substantial metabolism for carboxylic acid and esters are 477 plotted in the positive direction, while those with substantial metabolism for 478 carbohydrates are plotted in the negative direction. Meanwhile, the second principal 

among the sampling dates.

482 Activated sludge having different dilution levels are plotted with the data set taken on 48319 August. The fact that the three data plots are located at approximately the same 484 position indicates that the two digit differences in the copy numbers among the samples have little influence on the results of the principal component analysis.

The distribution of substrate metabolic patterns for the samples exhibited much in common among the sampling date. It was determined that similar substrate metabolic patterns, which metabolized carbohydrates to a high degree, were obtained for the activated sludge, influent to the SAT reactor and $0-5 \mathrm{~cm}$ layer. In comparison to these, quite a different metabolic pattern was demonstrated by the sand layers from 10 to 30 $\mathrm{cm}$, which metabolized carboxylic acid and esters to a high degree, and it is possible 493 that the metabolic pattern exhibited by the $5-10 \mathrm{~cm}$ layer is at a midpoint of the 494 changing pattern from the $0-5 \mathrm{~cm}$ layer to the $10-30 \mathrm{~cm}$ layers. This result suggests that 495 the SAT sand layers immediately below $5 \mathrm{~cm}$ from the top surface removes different 496 organic compounds by biodegradation than the aerobic tank in WWTP. This also means 497 that several organic compounds, which are not easily removed by the microbial 498 activities in the activated sludge, which is operated with limited HRT and SRT, are 
499 removed by microbial activities in the SAT sand layers below $5 \mathrm{~cm}$ from the top surface.

500 In addition, the boundary between the vadose zone and saturated zone was exhibited by

501 the 15-20 cm layer. Meanwhile, there were no changes observed in the metabolic

502 patterns of adjacent layers. Moreover, metabolic patterns demonstrated by the $87 \mathrm{~cm}$

503 layer, especially the $187 \mathrm{~cm}$ are unique.

504

$505 \quad 3.2 .4$. Water qualities along the flow path

506 SS and VSS for the activated sludge were (median (minimum-maximum)) 1140

507 (960-1360) and 975 (757-1200), respectively, while those for the influent to the SAT

508 reactor were $3.80(2.90-4.75) \mathrm{mg} / \mathrm{L}$ and $3.60(2.50-3.65) \mathrm{mg} / \mathrm{L}$, respectively.

509

510 Table 2 shows water qualities along the flow path. In addition, Figure 4 shows the

511 profiles of the water quality parameters in the SAT reactor. The $\mathrm{pH}$ of the water samples,

512 except for the effluent $(187 \mathrm{~cm})$ from the SAT reactor, were similar. Meanwhile, the

513 effluent $(187 \mathrm{~cm})$ from the SAT reactor was significantly lower than that of the effluent

$514(87 \mathrm{~cm})$ from the SAT reactor, as discussed previously. Median DO of the samples

515 varied from 1.47 to $4.34 \mathrm{mgO}_{2} / \mathrm{L}$ indicating that each water sample was under aerobic

516 conditions, as discussed previously.

517

518 Similar values of DOC were obtained for the activated sludge and influent to the SAT 
519 reactor $(p>0.05)$. Meanwhile, a significant decreasing trend along the percolation path 520 in the reactor was observed $(p<0.05)$, as discussed previously. In comparison to the 521 median DOC of the influent to the SAT reactor, the median DOC removal ratio of 522 effluent $(25 \mathrm{~cm})$ from the SAT reactor was $59.0 \%$. Therefore, it was determined that 523 over half the DOC of the influent to the SAT reactor was removed through $25 \mathrm{~cm}$ 524 percolation.

526 Similar values of $\mathrm{UV}_{254}$ and SUVA were obtained for the activated sludge and influent 527 to the SAT reactor $(p>0.05)$. Median $\mathrm{UV}_{254}$ decreased from the influent to the SAT 528 reactor to the effluent $(25 \mathrm{~cm})$ from the SAT reactor; however, it was not significant 529 ( $p>0.05)$. Meanwhile, SUVA significantly increased from the influent to the SAT reactor 530 to the effluent $(25 \mathrm{~cm})$ from the SAT reactor, and this indicated the preferential removal 531 of non-aromatic components through $25 \mathrm{~cm}$ percolation. $\mathrm{UV}_{254}$ significantly decreased 532 from the effluent $(25 \mathrm{~cm})$ from the SAT reactor to effluent $(87 \mathrm{~cm})$ from the SAT reactor $533(p<0.05)$; meanwhile, no significant difference was observed between the effluent $(25$ $534 \mathrm{~cm})$ from the SAT reactor and effluent $(87 \mathrm{~cm})$ from the SAT reactor $(p>0.05)$. There 535 were no significant differences for $\mathrm{UV}_{254}$ and SUVA between effluent $(87 \mathrm{~cm})$ from the 536 SAT reactor and effluent $(187 \mathrm{~cm})$ from the SAT reactor $(p>0.05)$.

538 Fluorescence EEM profiles of the activated sludge, influent to the SAT reactor, each 
539 effluent from the SAT reactor samples are given in Figure 5. In general, peaks in the 540 short range of excitation wavelengths (Ex)/emission wavelength (Em) $=<250 \mathrm{~nm} /<350$

$541 \mathrm{~nm}$ are related to simple aromatic proteins. Peaks in the range of $\mathrm{Ex} / \mathrm{Em}=250-280$

$542 \mathrm{~nm} /<380 \mathrm{~nm}$ are associated with soluble microbial by-product-like (SMP-like)

543 compounds. Peaks in the range of Ex/Em $=240-260 \mathrm{~nm} / 380-480 \mathrm{~nm}$ are related to

544 fulvic acid-like compounds. Peaks in the range of Ex/Em $=320-350 \mathrm{~nm} / 400-480 \mathrm{~nm}$

545 are associated with humic acid-like compounds (Chen et al., 2003; Xue et al., 2009).

547 Peaks representative of simple aromatic proteins, fulvic acid-like and humic acid-like 548 compounds were observed in the activated sludge and influent to the SAT reactor. 549 Meanwhile, effluent $(25 \mathrm{~cm})$ from the SAT reactor was dominated by SMP-like 550 compounds. In addition, peaks representative of simple aromatic proteins, fulvic 551 acid-like and humic acid-like compounds in effluent $(25 \mathrm{~cm})$ from the SAT reactor were 552 stronger than those in the influent to the SAT reactor. In comparison with the influent to 553 the SAT reactor, over half of the DOC was removed and the change of SUVA shows 554 preferential removal of non-aromatic components through $25 \mathrm{~cm}$ percolation. In 555 addition, Xue et al., (2009) determined that organic matter fractionated into hydrophilic 556 and transphilic neutral components were preferentially removed by SAT. Therefore, the 557 increase of the peaks indicated that the relative abundance of simple aromatic proteins, 558 fulvic acid-like and humic acid-like compounds increased because of the removal of 
559 such type of organic substances. In addition, the appearance of the SMP-like substance

560 peak was possible because of the contribution of biodegradation to the DOC removal

561 through $25 \mathrm{~cm}$ percolation. This was supported by Ak and Gunduz (2013a) who

562 clarified the active removal of organic carbon in the top $10 \mathrm{~cm}$ soil surface owing to

563 biodegradation. Because the peak for SMP-like substance was not observed in the case

564 of the effluent $(87 \mathrm{~cm})$ from the SAT reactor, SMP-like fluorescing compounds

565 observed in the effluent $(25 \mathrm{~cm})$ from the SAT reactor would have been removed. The

566 fluorescence data also suggested a decrease of simple aromatic proteins; meanwhile,

567 little change in the peaks representative of fulvic acid-like and humic acid-like

568 compounds was observed. With respect to the effluent $(87 \mathrm{~cm})$ from the SAT reactor,

569 little change in the peak representative of simple aromatic compounds was observed;

570 meanwhile, decrease of fulvic acid-like and humic acid-like compounds was exhibited

571 in the case of effluent $(187 \mathrm{~cm})$ from the SAT reactor. This suggests that the relative

572 abundance of fulvic acid-like and humic acid-like organic compounds decreased

573 because of their removal through percolation.

574

575 DTN in the activated sludge was significantly lower than that of the influent to the SAT

576 reactor $(p<0.05)$. In addition, DTN in the effluent $(25 \mathrm{~cm})$ from the SAT reactor was

577 significantly higher than that of the influent to the SAT reactor and the effluent $(87 \mathrm{~cm})$

578 from the SAT reactor $(p<0.05)$. Meanwhile, the relative abundance of $\mathrm{NO}_{3}{ }^{-}$was high 
579 (median: $68.3 \%-85.2 \%$ ) in each sample, as discussed previously.

580

581 DTP was detected in the activated sludge (median: $0.758 \mathrm{mgP} / \mathrm{L}$ ) and influent to the 582 SAT reactor (median: $0.400 \mathrm{mgP} / \mathrm{L}$ ); meanwhile, the concentration of $0.007 \mathrm{mgP} / \mathrm{L}$ in 583 the effluent $(25 \mathrm{~cm})$ from the SAT reactor was significantly lower than that of the 584 influent to the SAT reactor $(p<0.05)$. In addition, DTP was not detected in the $87 \mathrm{~cm}$ 585 and effluent $(187 \mathrm{~cm})$ from the SAT reactor samples $(<0.002 \mathrm{mgP} / \mathrm{L})$, as discussed 586 previously.

587

588 The median mole ratios of $\mathrm{C}: \mathrm{N}: \mathrm{P}$ were 100:92:21, 100:120:11, 100:350:0.47, $589100: 530:<0.23$ and 100:550: $<0.30$ for the activated sludge, influent to the SAT reactor, 590 effluent $(25 \mathrm{~cm})$ from the SAT reactor, effluent $(87 \mathrm{~cm})$ from the SAT reactor and 591 effluent $(187 \mathrm{~cm})$ from the SAT reactor, respectively, and it was determined that carbon 592 was the limiting factor for microbial activities in the activated sludge and influent to the 593 SAT reactor; meanwhile, phosphorus was the limiting factor in the effluent $(25 \mathrm{~cm})$ 594 from the SAT reactor, effluent $(87 \mathrm{~cm})$ from the SAT reactor and effluent $(187 \mathrm{~cm})$ from 595 the SAT reactor.

596

597 3.2.5. Relationships between the changes in substrate metabolic 598 patterns and water qualities 
599 There were similar substrate metabolic patterns among the activated sludge, influent to

600 the SAT reactor and $0-5 \mathrm{~cm}$ layer; meanwhile, those in sand layers below $5 \mathrm{~cm}$ were

601 quite different from these. In this section, relationships between the changes in substrate

602 metabolic patterns and water qualities are discussed.

603

604 First, it is suggested that DO concentrations have little influence on the change in 605 metabolic patterns because the activated sludge, influent to the SAT reactor and the SAT 606 reactor operated under aerobic conditions.

607

608 Comparing the water qualities between the activated sludge and influent to the SAT

609 reactor, no significant differences, including similar organic components by SUVA and

610 EEM, except for the relative abundance of nitrogen species, were observed. Meanwhile,

611 carbon was the limiting factor for microbial activities in both samples. Therefore, the

612 observed significant differences of nitrogen species are expected to have little influence

613 on the microbial substrate metabolism in these cases. Based on the results, similar

614 metabolic patterns should be observed because of a similar water environment.

615

616 The metabolic patterns in the $0-5 \mathrm{~cm}$ layer were also similar to those of the activated 617 sludge and influent to the SAT reactor. The influent to the SAT reactor, whose water 618 qualities were similar to the activated sludge and which contained microbes that 
619 originated from the activated sludge, was discharged onto the top SAT surface.

620 Therefore, it is possible that the similar water environment and the discharge of the

621 microbes would have an influence on the populations of microbes in the $0-5 \mathrm{~cm}$ layer,

622 resulting in metabolic patterns similar to that of the activated sludge and influent to the

623 SAT reactor.

624

625 Differences in the compositions of organic matter, as determined by SUVA and EEM,

626 and transit of the limiting factor from carbon to phosphorus were observed between the

627 influent to the SAT reactor and effluent $(25 \mathrm{~cm})$ from the SAT reactor. FDA assay of the

$6280-5 \mathrm{~cm}$ layer was significantly higher than that of the 5-10 $\mathrm{cm}$ layer $(p<0.05)$. In

629 addition, Quanrud et al., (1996) showed that $8 \mathrm{~cm}$ percolation of the vadose zone

630 removed DOC from 8.6 to $6.7 \mathrm{mgC} / \mathrm{L}$, and active removal was obtained by only $8 \mathrm{~cm}$

631 percolation. Therefore, it is possible that the active DOC removal occurring in the $0-5$

$632 \mathrm{~cm}$ layer had the largest contribution to the change in the composition of organic matter

633 between the influent to the SAT reactor and effluent $(25 \mathrm{~cm})$ from the SAT reactor,

634 which is reflected by the different metabolic patterns observed between the $0-5 \mathrm{~cm}$

635 layer and layers from 5 to $30 \mathrm{~cm}$. In addition, it is also possible that microbial activity in

636 the $0-5 \mathrm{~cm}$ layer had the largest contribution to the change of the limiting factor from

637 carbon to phosphorus. Kunimoto and Nagaoka (2009) showed that BIOLOG assay

638 using ECO plate significantly differentiated metabolic patterns of microbes in forest soil, 
639 which was cultivated with and without the addition of nitrogen and phosphorus.

640 Therefore, it is also possible that the observed changes in metabolic patterns can be

641 attributed to the changes in the limiting factor.

642

643 The large differences in the composition of organic matter can be partly contributed to

644 the change of metabolic patterns between the $87 \mathrm{~cm}$ layer and the layers above. In

645 addition, the change of the composition of organic matter and significantly low $\mathrm{pH}$ of

646 the effluent $(187 \mathrm{~cm})$ from the SAT reactor should contribute to the unique metabolic

647 patterns observed there.

648

649

\section{4. Conclusions}

651 In this study the changes in the microbial substrate metabolic patterns by using the

652 BIOLOG assay were discussed through a sequential wastewater reuse process, which

653 includes activated sludge and treated effluent in WWTP and SAT, especially focusing

654 on the surface sand layer in conjunction with the vadose zone. The substrate patterns in

655 SAT were analysed using a pilot-scale reactor, in which stable water quality parameters

656 were obtained. The major conclusions are as follows:

657 (1) FDA assay revealed that microbial activities in sand significantly decreased at a 658 depth greater than $5 \mathrm{~cm}$ from the top surface in SAT $(0-5 \mathrm{~cm}$ layer: $0.090,5-10 \mathrm{~cm}$ 
659 layer: $0.042,10-15 \mathrm{~cm}$ layer: 0.012 and $15-20 \mathrm{~cm}$ layer: $0.005 \mathrm{~cm}^{-1} \cdot \mathrm{g}$-dry ${ }^{-1}$ ).

660 (2) Similar microbial metabolic patterns with preferential carbohydrates were obtained

661 among the activated sludge, the influent to the SAT reactor and the $0-5 \mathrm{~cm}$ sand

662 layer. In addition, the 10-30 $\mathrm{cm}$ sand core layers showed dramatically different

663 metabolic patterns with high degree of carboxylic acid and esters. Thus, it is

664 possible that the metabolic pattern exhibited by the $5-10 \mathrm{~cm}$ layer is at the midpoint

665 of the changing pattern. This suggests that the removal of different organic

666 compounds by biodegradation is expected to occur in the activated sludge and in the

667 SAT sand layers immediately below $5 \mathrm{~cm}$ from the top surface.

668 (3) There were no significant differences, including similar organic components,

669 between the activated sludge and the influent to the SAT reactor, and similar

670 metabolic patterns between them should be observed because of similar water

671 environment. In addition, it is possible that the similar water environment and the

672 discharge of microbes would affect the populations of microbes in the $0-5 \mathrm{~cm}$ layer,

673 resulting in metabolic patterns similar to those of the activated sludge and influent to

674 the SAT reactor.

675 (4) DOC significantly decreased from the influent to the SAT reactor $(3.68 \mathrm{mgC} / \mathrm{L})$ to 676 the effluent $(25 \mathrm{~cm})$ from the SAT reactor $(1.52 \mathrm{mgC} / \mathrm{L})$. The composition of 677 organic matter also changed between them, represented as domination by SMP-like 678 compounds in the effluent $(25 \mathrm{~cm})$ from the SAT reactor, which suggests the 
679 contribution of biodegradation to the DOC removal via $25 \mathrm{~cm}$ percolation. DTN

680 significantly increased from the influent to the SAT reactor $(4.43 \mathrm{mgN} / \mathrm{L})$ and to the

681 effluent $(25 \mathrm{~cm})$ from the SAT reactor $(5.11 \mathrm{mgN} / \mathrm{L})$; whereas DTP significantly

682 decreased from 0.400 to $0.007 \mathrm{mgP} / \mathrm{L}$. Consequently, limiting factor for microbial

683 activities was carbon in the influent to the SAT reactor (C:N:P = 100:120:11);

684 meanwhile it was phosphorus in the effluent $(25 \mathrm{~cm})$ from the $\mathrm{SAT}$ reactor $(\mathrm{C}: \mathrm{N}: \mathrm{P}=$

$685100: 350: 0.47)$. Therefore, changes in the composition of organic matter and/or the

686 transition of the limiting factor for microbial activities from carbon to phosphorus

687 may contribute to the observed dramatic changes in the SAT metabolic patterns.

688

689

690 Acknowledgement

691 This study was supported by CREST/JST, and we thank Kyoto City Waterworks Bureau

692 for their support of the experiments.

693

694

695 References

696 Ak, M., Gunduz, O., 2013a. Comparison of organic matter removal from synthetic and

697 real wastewater in a laboratory-scale soil aquifer treatment system, Water Air Soil

698 Pollution, 224:1467. 
699 Ak, M., Gunduz, O., 2013b. Fate of nutrients in secondary treated municipal wastewater 700 during percolation through the soil media, Clean - Soil Air Water, 41 (9999), 1-8.

701

702 Alfreider, A., Krössbacher, M., Psenner, R., 1997. Groundwater samples do not reflect 703 bacterial densities and activity in subsurface systems, Water Research, 31 (4), $704 \quad 832-840$.

705

706 Al-Mutairi, N.Z., 2009. Variable distributional characteristics of substrate utilization 707 patterns in activated sludge plants in Kuwait, Bioresoruce Technology, 100 (4), $708 \quad 1524-1532$.

709

710 Asano, T., Burton, F.L., Leverenz, H.L., Tsuchihashi, R., Tchobanoglous, G., 2007.

711 Water reuse: issues, technologies and applications, 1248-1249, Metcalf and Eddy, 712 Inc., US.

713

714 Asano, T., Cotruvo, J.A., 2004. Groundwater recharge with reclaimed municipal 715 wastewater: health and regulatory considerations, Water Research, 38 (8), 1941-1951.

716

717 Campbell, C.D., Grayston, S.J., Hirst, D.J., 1997.Use of rhizosphere carbon sources in 718 sole carbon source tests to discriminate soil microbial communities, Journal of 
719 microbiological methods, 30 (1), 33-41.

720

721 Chalmers, R.B., Patel, M., 2013. Key to success of groundwater recharge with recycled 722 water in California, Milestones in Water Reuse, 297-314, IWA Publishing, UK.

723

724 Chen, W., Westernhoff, P., Leenheer, J.A., Booksh, K., 2003. Fluorescence

725 excitation-emission matrix regional integration to quantify spectra for dissolved 726 organic matter, Environmental Science and Technology, 37, 5701-5710.

727

728 Drewes, J.E., Fox, P., 1999. Fate of natural organic matter (NOM) during groundwater 729 recharge using reclaimed water, Water Science and Technology, 40 (9), 241-248.

730

731 Garland, J.L., 1996. Analytical approaches to the characterization of samples of 732 microbial communities using patterns of potential C source utilization, Soil Biology 733 and Biochemistry, 28 (2), 213-221.

734

735 Garland, J.L., Mills, A.L., 1991. Classification and characterization of heterotrophic 736 microbial communities on the basis of patterns of community-level 737 sole-carbon-source utilization, Applied and Environmental Microbiology, 57 (8), $738 \quad 2351-2359$. 
739 Guckert, J.B., Carr, G.J., Johnson, T.D., Hamm, B.G., Davidson, D.H., Kumagai, Y.,

740 1996. Community analysis by Biolog: curve integration for statistical analysis of

741 activated sludge microbial habitats, Journal of Microbiological methods, 27, 183-197.

742

743 Hazen, T.C., Jimenéz, L., de Victoria, G.L., Fliermans, C.B., 1991. Comparison of

744 bacteria from deep subsurface sediment and adjacent groundwater, Microbial Ecology,

$745 \quad 22,293-304$.

746

747 Ichikawa, T., Takahashi, T., Asano, Y., Kobayashi, T., 2002. A simple method of

748 measuring microbial activities in forest using a FDA (fluorescein diacteate)

749 hydrolysis, Japanese Society of Forest Environment, 44 (2), 15-22.

750

751 Japan Sewage Works Association, 1997. Sewage water testing method, 296-297, Japan

752 Sewage Works Association, JP (in Japanese).

753

754 Kolehmainen, R.E., Korpela, J.P., Münster, U., Puhakka, J.A., Tuovinen, O.H., 2009.

755 Extracellular enzyme activities and nutrient availability during artificial groundwater

756 recharge, Water Research, 43 (2), 405-416.

757

758 Kyoto City Waterworks Bureau. Annual wastewater quality report in 2012 and 2013 (in 
759 Japanese)

760

761 Kunimoto, T., Nagaoka, K., 2009. Effects of plant litter type and additions of nitrogen

762 and phosphorus on bacterial community-level physiological profiles in a brown forest

763 soil, Microbes and Environment, 24 (1), 68-71.

764

765 Långmark, J., Storey, M.V., Ashbolt, N.J., Stenström, T.A., 2004. Artificial groundwater

766 treatment: biofilm activity and organic carbon removal performance, Water Research,

$767 \quad 38(3), 740-748$.

768

769 Oren, O., Gavrieli, I., Burg, A., Guttman, J., Lazar, B., 2007. Manganese mobilization

770 and enrichment during soil aquifer treatment (SAT) of effluents, the Dan Region

771 Sewage Reclamation Project (Shafdan), Israel, Environmental Science and

772 Technology, 41, 766-772.

773

774 Quanrud, D.M., Arnold, L.G., Wilson, R.G., Gordon, H.J., Graham, D.W., Amy, G.L.,

775 1996. Fate of organics during column studies of soil aquifertreatment, Journal of 776 Environmental Engineering, 122 (4), 314-321.

777

778 Quanrud, D.M., Hafer, J., Karpiscak, M.M., Zhang, J., Lanseya, K.E., Arnold, R.G., 
779 2003. Fate of organics during soil-aquifer treatment: sustainability of removals in the 780 field, Water Research, 37 (14), 3401-3411.

781

782 Rutgers, M., Breure, A.M., Insam, H., 2008. Substrate utilization in Biolog ${ }^{\mathrm{TM}}$ Plates for 783 analysis of CLPP, microbiological methods for assessing soil quality, 212-227, CABI. 784

785 Sala, M.M., Balagué, V., Pedrós-Alió, C., Massana, R., Felipe, J., Arin, L., Illoul, H., 786 Estrada, M., 2005. Phylogenetic and functional diversity of bacterioplankton during 787 Alexandrium spp. Blooms, FEMS Microbiology Ecology, 54 (2), 257-267.

788

789 Salomo, S., Münch, C., Röske, I., 2009. Evaluation of the metabolic diversity of 790 microbial communities in four different filter layers of a constructed wetland with $791 \quad$ vertical flow by Biolog ${ }^{\mathrm{TM}}$ analysis, Water Research, 43 (18), 4569-4578.

792

793 Schnürer, J., Rosswall, T., 1982. Fluorescein diacetate hydrolysis as a measure of total 794 microbial activity in soil and litter, Applied and Environmental Microbiology, 43 (6), $795 \quad 1256-1261$.

796

797 Schütz, K., Kandeler, E., Nagel, P., Scheu, S., Ruess, L., 2010. Functional microbial 798 community response to nutrient pulses by artificial groundwater recharge practice in 
799 surface soils and subsoils, FEMS Microbiology Ecology, 72 (3), 445-455.

800

801 Thawornchaisit, U., Pakulanon, K., 2007. Application of dried sewage sludge as phenol 802 biosorbent, Bioresource Technology, 98 (1), 140-144.

803

804 Wardle, D.A., 1992. A comparative assessment of factors which influence microbial 805 biomass carbon and nitrogen levels in soil, Biological Reviews, 67 (3), 321-358.

806

807 Weber, K.P., Legge, R.L., 2011. Dynamics in the bacterial community-level 808 physiological profiles and hydrological characteristics of constructed wetland 809 mesocosms during start-up, Ecological Engineering, 37 (5), 666-677.

810

811 Xue, S., Zhao, Q., Wei, L., Ren, N., 2009. Behavior and characteristics of dissolved 812 organic matter during column studies of soil aquifer treatment, Water Research, 43

$813 \quad(2), 499-507$.

814

815 Xue, W.C., Wu, C.Y., Xiao, K., Huang, X., Zhou, H.D., Tsuno, H., Tanaka, H., 2010.

816 Elimination and fate of selected micro-organic pollutants in a full-scale 817 anaerobic/anoxic/aerobic process combined with membrane bioreactor for municipal 818 wastewater reclamation, Water Research, 44 (20), 5999-6010. 
819 Zhang, X., Zhao, X., Zhang, M., 2012. Functional diversity changes of microbial 820 communities along a soil aquifer for reclaimed water recharge, FEMS Microbiology $821 \quad$ Ecology, $80(1), 9-18$. 
Table 1 Ranges of TOC and FDA, 16S rRNA copy numbers and results of the Wilcoxon rank sum test, where ranges are given as median (minimum-maximum)

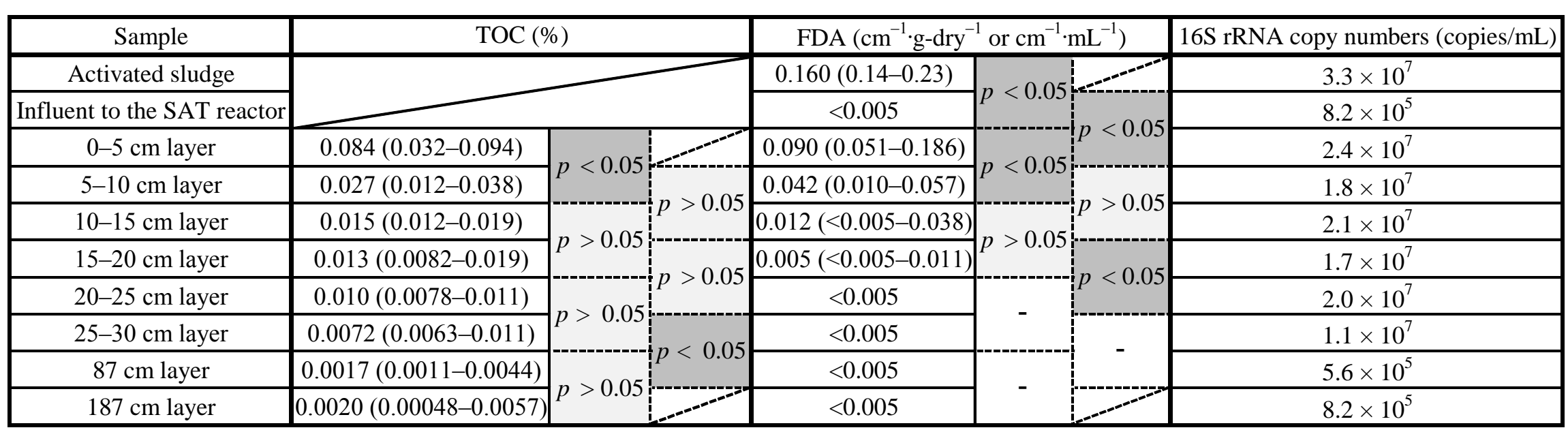


Table 2 Ranges of water quality index and results of the Wilcoxon rank sum test, where ranges are given as median

(minimum-maximum)

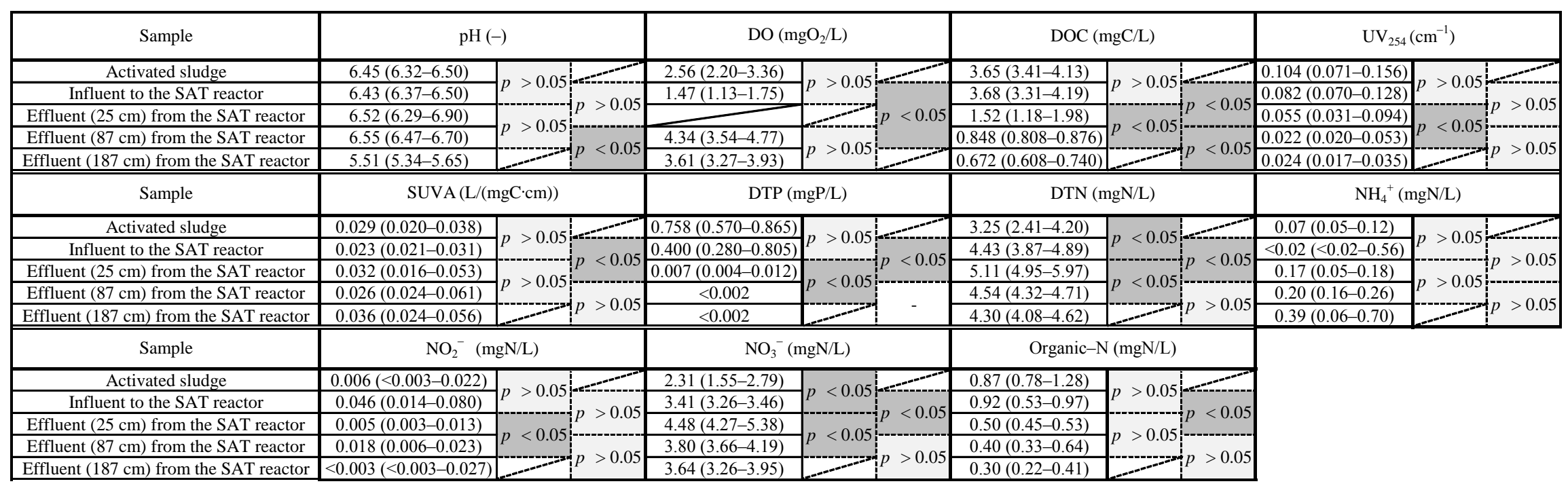




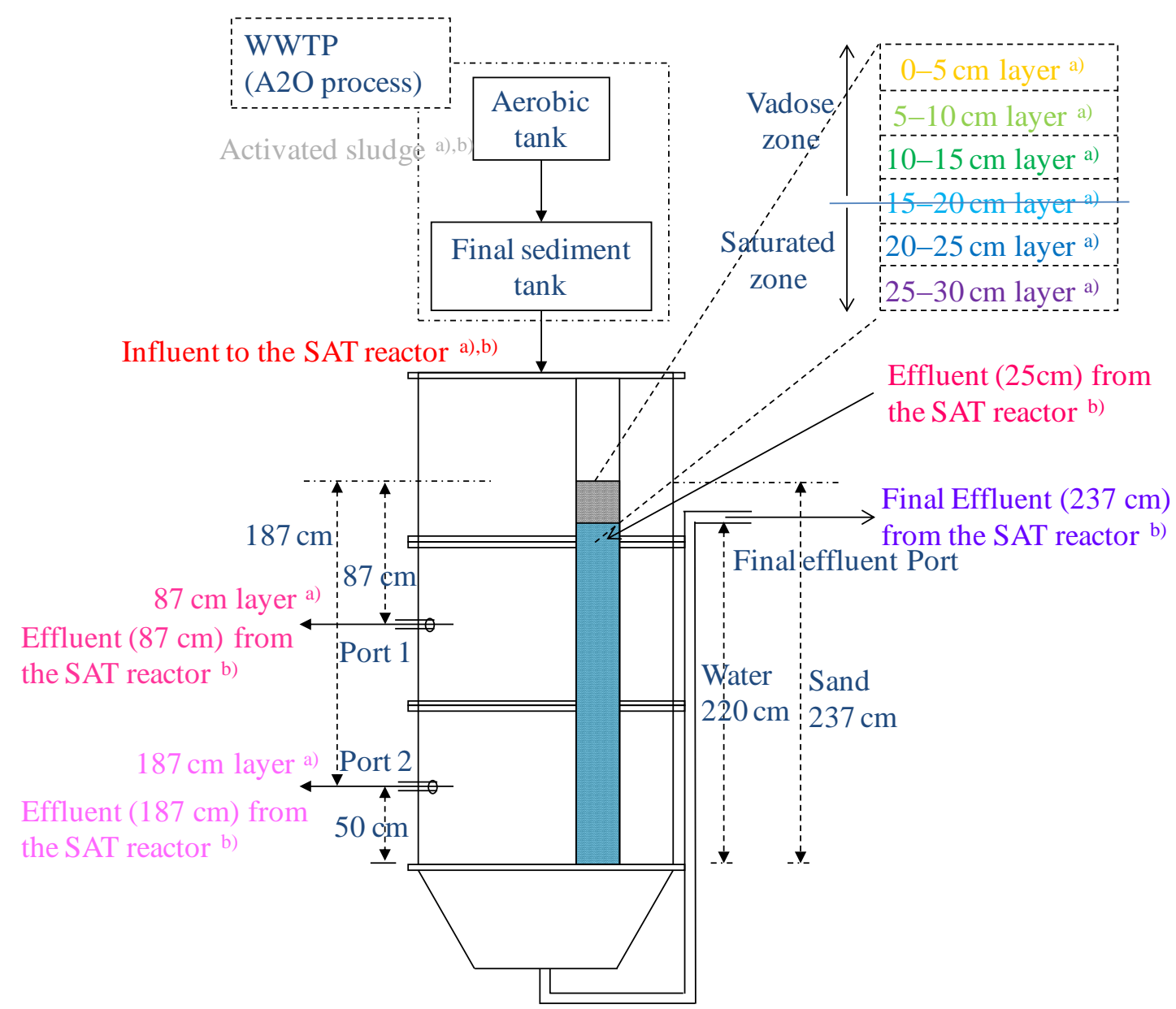

Figure 1 Diagram of the SAT reactor and designations of various treated water and layer samples: (a) samples used for the determination of substrate metabolic patterns and (b) samples used for the determination of water qualities 
$\diamond$ Influent to the SAT reactor $\quad \square$ Effluent $(87 \mathrm{~cm})$ from the SAT reactor $\quad \Delta$ Effluent $(187 \mathrm{~cm})$ from the SAT reactor $\quad \bullet$ Final effluent $(237 \mathrm{~cm})$ from the SAT reactor $*$ Water temperature in the final effluent
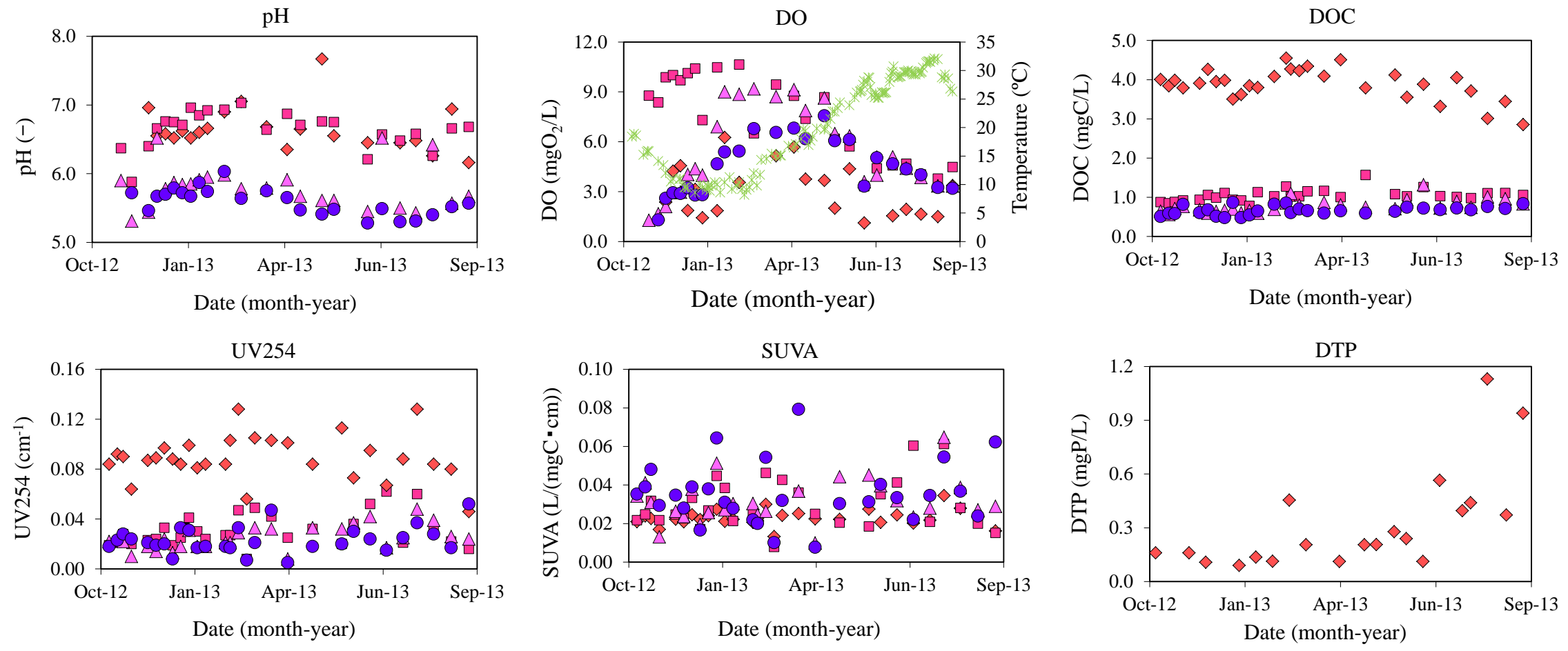

Figure 2-1 Temporal changes in $\mathrm{pH}, \mathrm{DO}, \mathrm{DOC}, \mathrm{UV}_{254}$, SUVA and DTP for treated water sampled from various points of the SAT reactor 
$\diamond \mathrm{DTN} \quad \square \mathrm{NH}_{4}{ }^{+} \quad \triangle \mathrm{NO}_{2}^{-} \quad \times \mathrm{NO}_{3}^{-} \quad *$ Organic-N
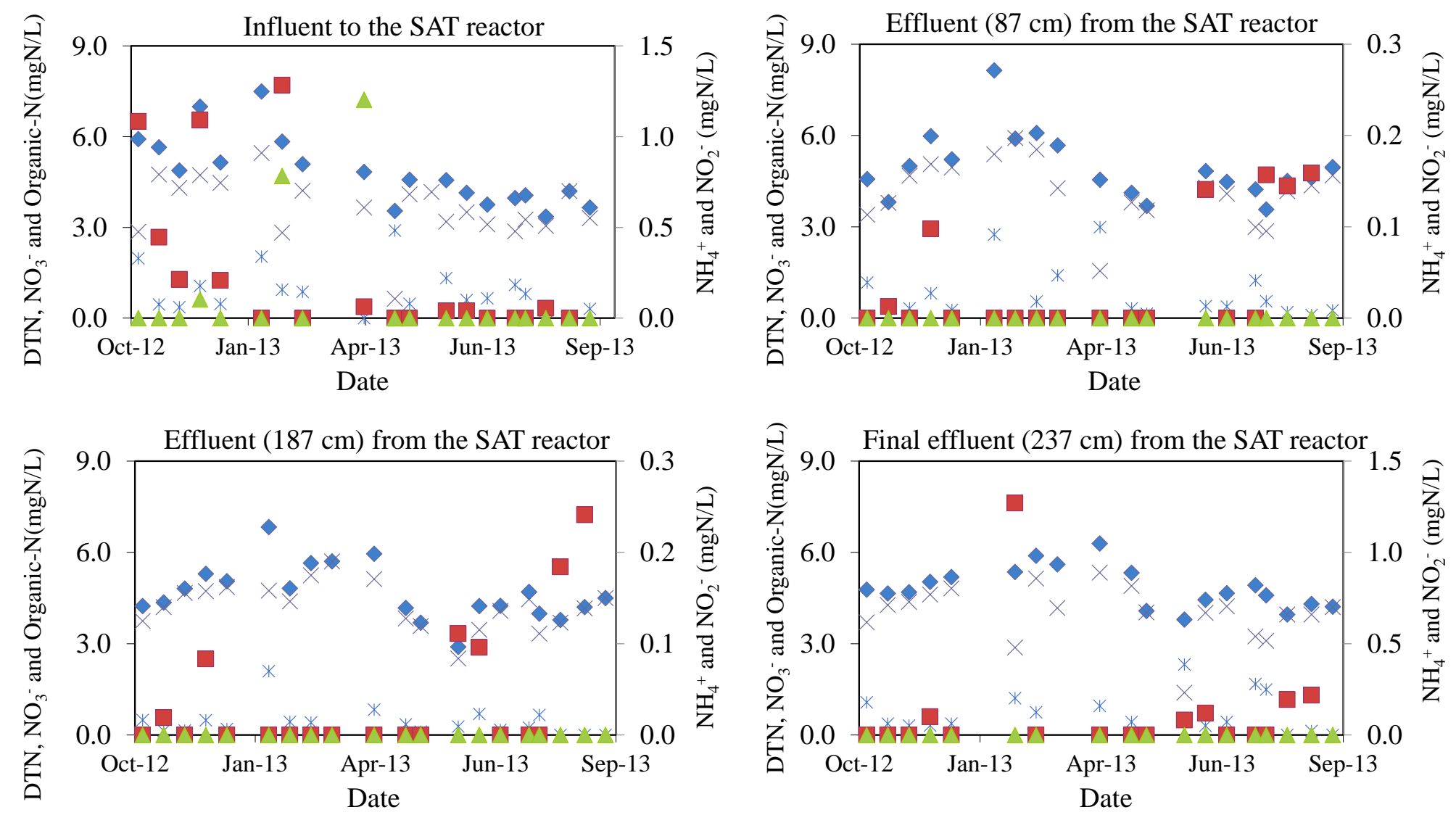

Figure 2-2 Temporal changes in DTN and its components for treated water sample from various points of the SAT reactor 

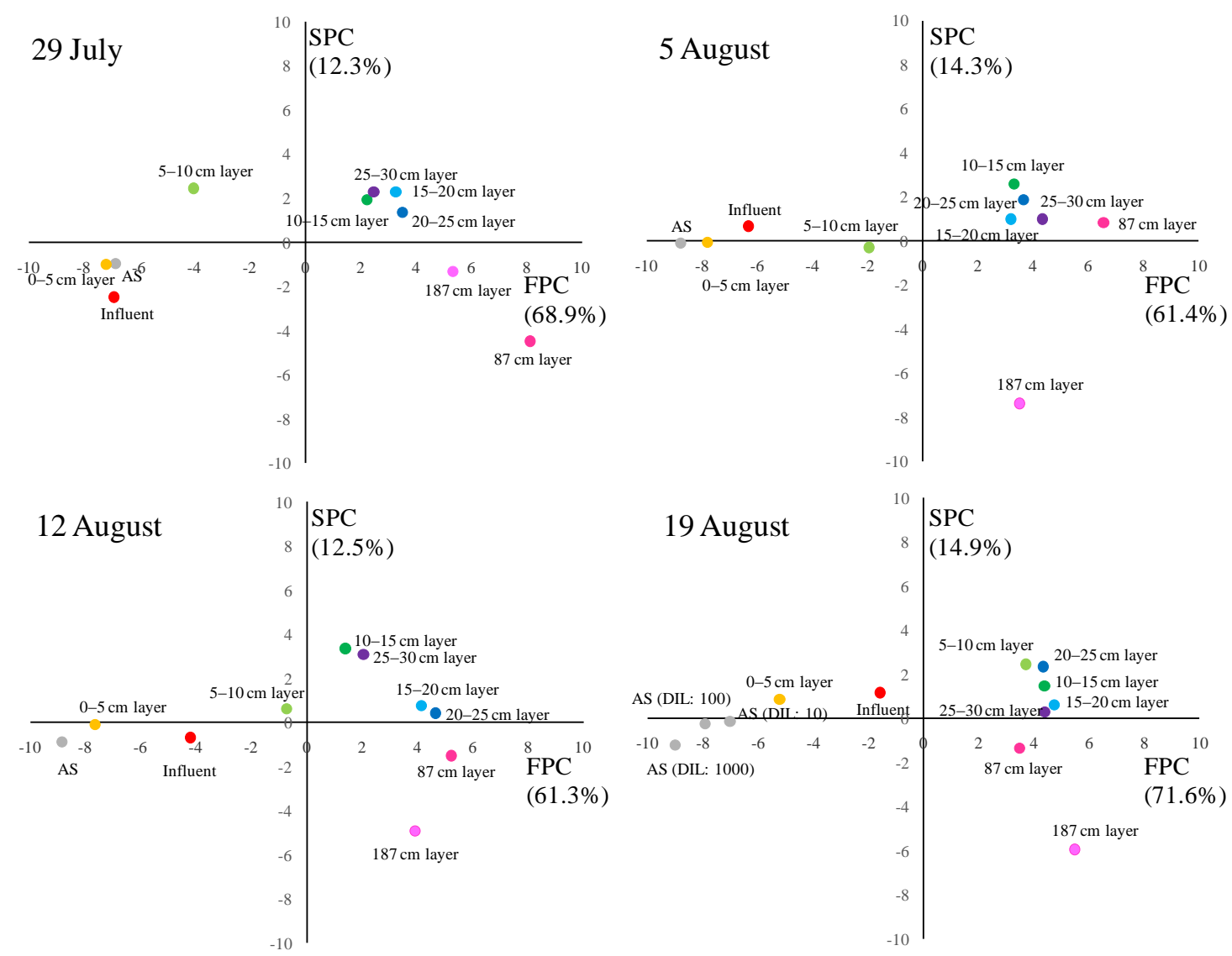

Figure 3 Changes of microbial substrate metabolic patterns at each sampling event, where FPC refers to the first principal component, SPC to the second principal component, AS to activated sludge, Influent to influent to SAT reactor and DIL to dilution 

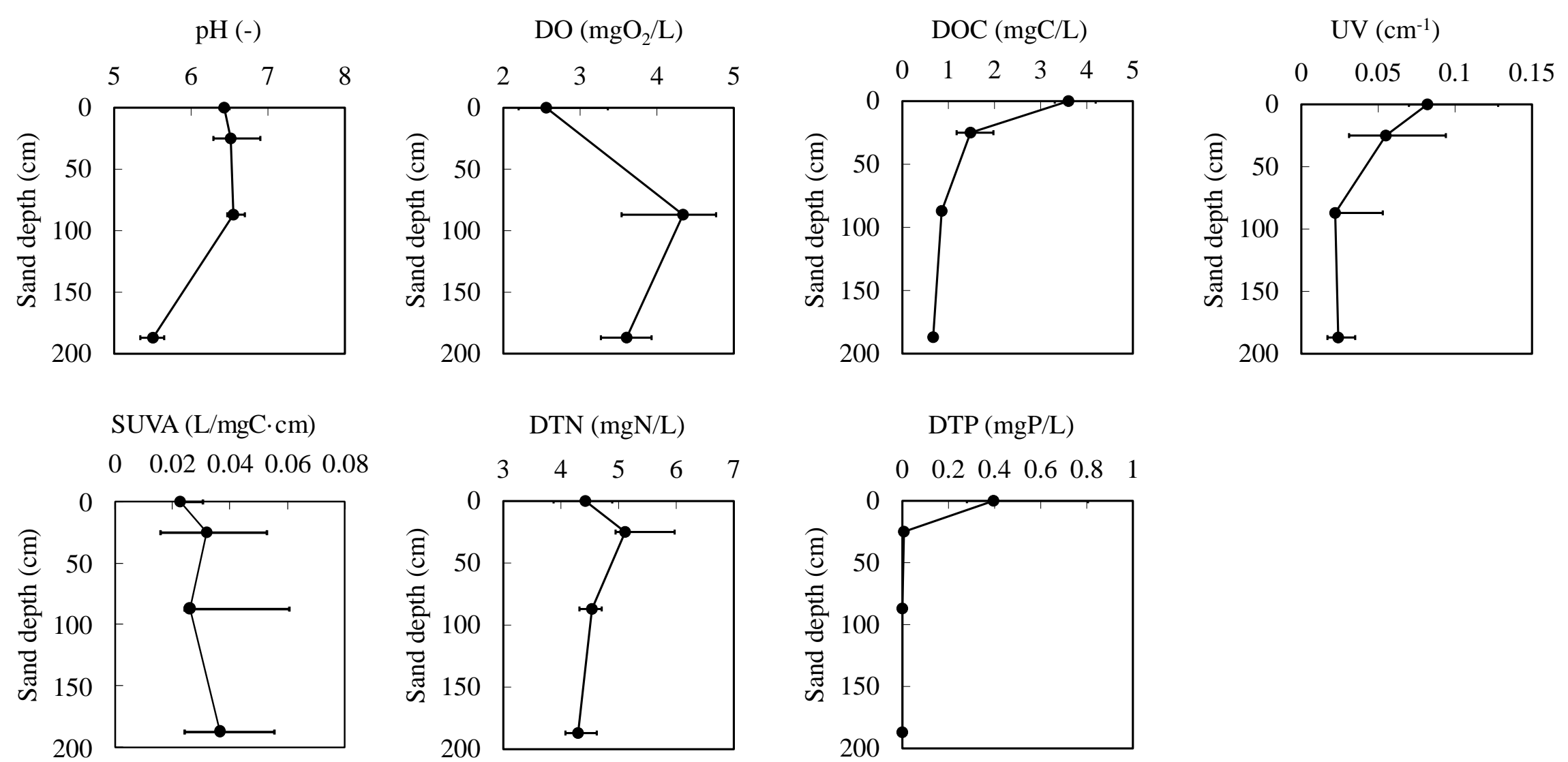

$\mathrm{DTP}(\mathrm{mgP} / \mathrm{L})$

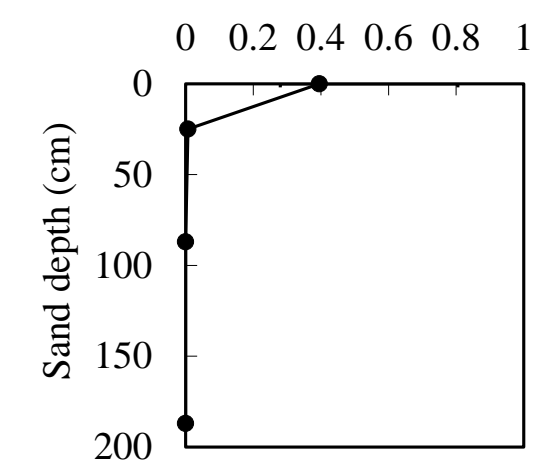

Figure 4 Profiles of the water quality parameters in the SAT reactor. Plot and bars show median, and minimum and maximum values,

respectively 


$\begin{array}{lllll}\square 285-300 & \square 270-285 & \square 255-270 & \square 240-255 & \square 225-240 \\ \square 210-225 & \square 195-210 & 180-195 & \square-165-180 & \square 0-150 \\ \square 135-150 & \square 120-135 & \square 105-120 & \square 0-105 & \square 5-90 \\ \square 60-75 & \square 45-60 & \square 30-45 & \square 15-30 & \square 0-15\end{array}$
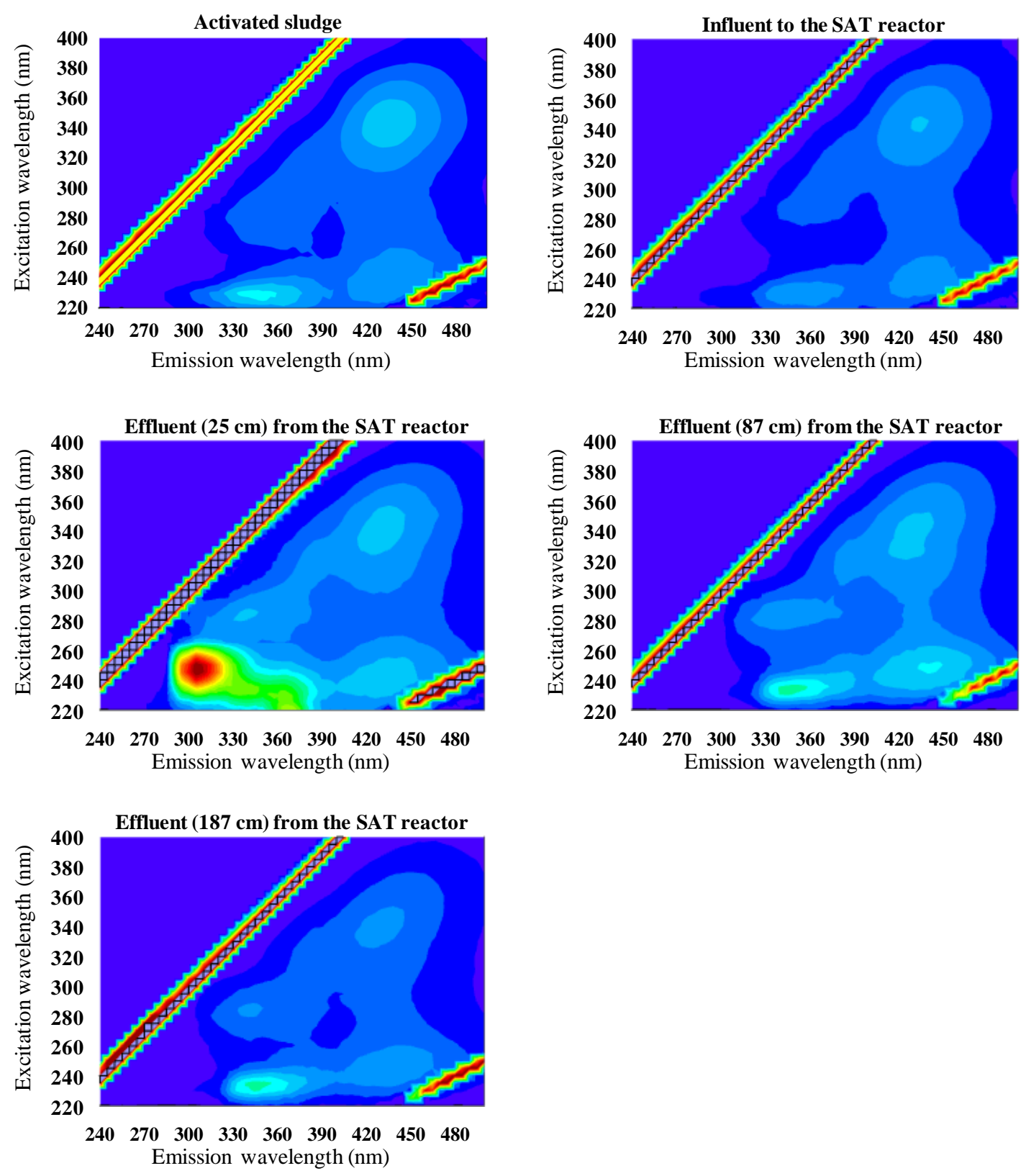

Figure 5 Fluorescence emission-excitation matrices (EEM) profiles of treated water samples from various points of the SAT reactor 
Change of microbial substrate metabolic patterns by BIOLOG assay through a wastewater reuse process, including WWTP and SAT

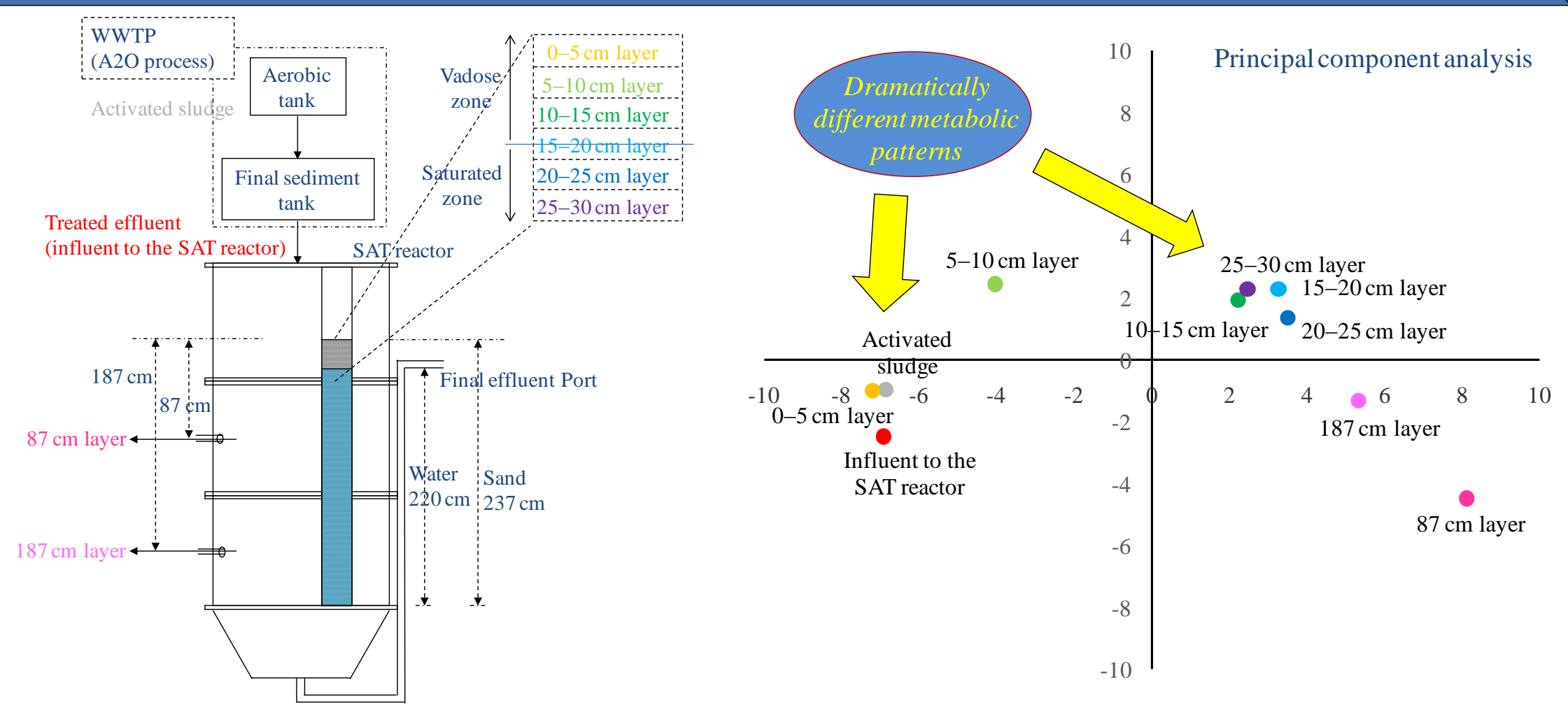

